\title{
STUDY ON STRESS LEVEL IN ELITE JUNIOR GYMNASTS
}

\author{
Georgeta MITRACHE $^{1 *}$, Aura BOTA ${ }^{1}$, Constanța URZEALĂ ${ }^{1}$, Ștefania CHIRIAC ${ }^{1}$ \\ ${ }^{1}$ National University of Physical Education and Sport, Faculty of Physical Education and Sport, Bucharest, Romania \\ *Corresponding author: ritmicuta@gmail.com
}

DOI: 10.35189/iphm.icpesk.2019.21

\begin{abstract}
The aim of this study is to identify the level and main sources of stress as perceived by elite junior rhythmic gymnasts. Given that the Romanian Olympic Committee is interested in developing a programme meant to encourage junior gymnasts specialising in group event, we intend to monitor these parameters from the starting point of this team and contribute to increasing their ability to manage training and competition stress. The participants in this study were 10 junior gymnasts aged between 10 and 12 years, representing the National Rhythmic Gymnastics Group. Our research was carried out during the basic training period, followed by an assessment during the precompetitive period, prior to the European Junior Championships. The study used the Cognitrom Profile of Emotional Distress test as a research tool to assess the gymnasts' subjective experiences linked to their emotions and negative feelings related to their first long-term preparation stage in a centralised national training campus. Additionally, the subjects were asked to reveal their main sources of stress related to sports practice. The gymnasts were at first in an adjusting period, trying to cope with being away from family, different school settings, new teammates and coach, as well as dealing with different technical requirements during group routines. In the second assessment, their level of stress increased, its sources being different and related to the proximity of the competition. Our study emphasised a specific dynamics in the profile of emotional distress according to the periodisation framework, underlining the importance of developing appropriate coping mechanisms.
\end{abstract}

Keywords: junior rhythmic gymnasts, emotional distress, group event.

\section{Introduction}

Given the complex requirements of today's rhythmic gymnastics, in somatic, functional, motor and cognitiveemotional terms, one can hardly imagine the achievement of high performance in this sport without the continuous support of psychological training.

A professional rhythmic gymnast experiences a myriad of states linked to maintaining an optimal weight (Pehlivan, Nalçakan, \& Ergan, 2018), processing a large amount of sensory information and consequently mastering different apparatus techniques and high-intensity training loads with perfect neuromotor control, as well as negative feelings of panic or psychological breakdown induced by the over-influence of adrenergic systems in all functional structures.

Among the psychological constructs that either decrease or facilitate motor behaviour, stress and anxiety, or the optimum level of arousal/activation, are essential aspects that have to be continuously addressed throughout the training process, but with a special emphasis in the competitive stage. Most references indicate a certain relationship between arousal and sport performance, which is definitely applicable in rhythmic gymnastics. Complex technical skills (body difficulties, apparatus handling, dynamic elements with rotation, dance step combinations) are better performed when the activation level is relatively low, while simple tasks can be completed with a high activation level.

In an attempt to determine the factors involved in competitive rhythmic gymnastics performance, Bobo-Arce and Méndez-Rial (2013) present a critical review of the literature on this topic including the psychological area of sports training. Several authors (Daroglou, 2011; Fan, Cao, \& Tang, 2004) explain various psychological dimensions in elite rhythmic gymnastics, bringing relevant information about anxiety state and its influence on performance, as well as trait anxiety versus competitive state anxiety. Applying the Competitive State Anxiety Inventory with its three subscales (cognitive anxiety, somatic anxiety and self-confidence) leads to the idea that only self-confidence has positive effects on performance, while cognitive and somatic anxiety has no influence on the results, these data confirming the Multidimensional Anxiety Theory of Martens, Vealey and Burton (1990) (Tsopani, Dallas, \& Skordilis, 2011).

Fletcher and Fletcher (2005) assert that each competition presents a potential stressor for athletes depending on the expected outcomes and the goal achievement, which leads to precompetitive anxiety. The more important the competition, the higher the intensity of this negative state, meaning that each athlete should train their psychological resilience in order to overcome increased tension.

However, some authors report that many athletes enjoy the optimal tension associated with a competition, which is a good indicator of their readiness to perform (Jemni, Sands, Salmela, Holvoet, \& Gateva, 2011, p. 139). 
In these circumstances, gymnasts can reshape a potentially harmful threat into an exciting challenge that involves concentration, confidence and control (Jones, Hanton, \& Connaughtoun, 2002). More specifically, according to Loehr (1995), mentally tough athletes have learned two important skills: the ability to increase and use positive energy and the ability to properly manage problems, pressure and possible errors in the competition routines. Furthermore, mental toughness is also seen as a personality trait related to "internal locus of control and selfefficacy" (Gibson, 1998).

Theoretically, stress is generally perceived in a negative way, depending on the stimuli involved and the athlete's psychological profile. Dantzer (2007, p. 750) distinguishes between positive stress - eustress (wherein the subject perfectly manages the situation) and negative stress - distress (which is potentially harmful and limits the resilience ability). In addition, stress can be divided into internal stress - generated by the athlete (their own expectations) and external stress (generated by other athletes, the coaching style, etc.). Studies reveal that many athletes evaluate themselves (self-worth) only by their sports results. This might be considered a hindrance to the athletes' ability to bounce back from failure. On the contrary, those who can separate the results from their selfworth can further regain energy and focus on the future challenges (Cohn, 2018).

In rhythmic gymnastics, the stressors overlap, increasing the inner tension and cumulating various reactions depending on the personality traits, stress appraisal, experience, training level, relevance of the competition, team nominees and strength of the competitors, or nationality of the judges.

The same topic is described in Table 1 (according to Hahn, 1987).

Table 1. Stressors in sports performers

\begin{tabular}{ll}
\hline \multicolumn{1}{c}{ Stressors } & \multicolumn{1}{c}{ Examples } \\
\hline Monotony & Lack of variation in the training content, large volumes \\
Psychological training & Inadequate means and methods for the athlete's particularities \\
Training content & Overload or insufficient training load \\
Lack of training outcomes & No correlation between the training content and outcomes \\
Psycho-social environment & Negative interactions between teammates, poor cooperation with the coach \\
\hline
\end{tabular}

Duda and Gano-Overway (1996) define stress response as a result of a perceptual process, which is why psychologists and coaches need to identify the perceived stress of gymnasts and help them develop an appropriate coping mechanism. The above authors state that the main sources of stress (according to sports psychology research) are: low perceived mental and physical readiness, increased fatigue, fear of errors or failure, pressure of high expectations, fear of negative evaluation.

Sports literature is familiar with the "fight or flight" phrase (also known as acute stress response). It describes an instinctual reaction of the athlete when faced with a real or only imaginary threat. Emerging from physiological mechanisms, the "flight mood" refers to fear, nervousness and most of the time "playing it safe" during competition. On the opposite side, "the fight mood" relates to embracing the sports challenge, enjoying the competition and converting negative stressors into fuel for engaging in a race (Yeh, 2016, p. 10).

Anshelm (2001) proposes a coping model for acute stress in sports competitions, which includes four chronological steps: perceiving a stimulus, appraising the stimulus as stressful, using coping strategies consisting of cognitive or behavioural strategies, adopting post-coping actions that involve either reappraising the stressful situation and examining how efficient the coping strategy was or giving up any sports tasks. This model regards the conceptualisation of stress in relation to one of the basic responses: fight or flight.

\section{Purpose of the study}

The purpose of this study is to identify the level and main sources of stress as perceived by elite junior rhythmic gymnasts, given that stress may disrupt their performance capacity. In addition, we aim to analyse the differences in emotional distress between the two tests.

\section{Hypothesis}

We assume that significant differences in emotional distress can be identified between the basic and precompetitive training periods in elite junior rhythmic gymnasts. 


\section{Material and Methods}

\section{Subjects}

The participants were 10 rhythmic gymnasts aged between 10 and 12 years, competing in the National Junior Team for individual (4 gymnasts) and group events (6 gymnasts). This team was formed in November 2018 following a national selection, the gymnasts being champions in individual or team events in internal competitions. Three of them were from UNEFS Bucharest, one from CSM Ploiești, one from LPS Oradea and five from CSM Arad.

The subjects included in this study train at the Arad Olympic Junior Centre coordinated by coach Daniela Chiriac in order to participate in the Rhythmic Gymnastics European Championships and World Championships for the group event.

According to the ethical research procedures, gymnasts willingly participated in the study, informed consents being signed by their parents. All subjects were clinically healthy.

\section{Procedure}

Given that the Romanian Olympic Committee is interested in developing a programme as a new strategy meant to encourage junior gymnasts specialising in group event, we intended to monitor stress level from the starting point of this team, contributing in the long run to increasing their ability to manage training and competition stress.

Our research was carried out during the basic training period, followed by an assessment during the precompetitive period, prior to the European Junior Championships. The study used the Emotional Distress Profile test (Copyright@Daniel David, the Romanian version) from the Cognitrom Assessment System (CAS++ v.2) (2012), including a 25-item questionnaire based on the short version of the Profile of Mood Disorders. This tool assessed the gymnasts' subjective experiences linked to their emotions and negative feelings related to their first long-term preparation stage in a centralised national training campus. An overall score of emotional distress was available.

Additionally, the subjects were asked to reveal their main sources of stress related to sports practice and report a typical situation that emotionally disturbed them during training or competition. The various types of responses were classified into main categories that received several iterations. The assessments took place at the "Sydney 2000" Olympic Training Centre of Izvorani and the UNEFS Psychology Laboratory in February and May 2019 during two training stages, according to the schedule agreed with the Romanian Olympic Committee.

\section{Results}

Descriptive statistics for the overall score of emotional distress calculated for the basic training period are shown in Table 2.

Table 2. Descriptive statistics for the overall score of emotional distress - Basic training period

\begin{tabular}{lc}
\hline \multicolumn{2}{l}{ Overall score of emotional distress - Basic training period } \\
\hline Mean & 23.5 \\
Standard Error & 2.646801 \\
Median & 23 \\
Mode & 20 \\
Standard Deviation & 8.36992 \\
Sample Variance & 70.05556 \\
Kurtosis & 1.23038 \\
Skewness & -0.65659 \\
Minimum & 6 \\
Maximum & 36 \\
Count & 10 \\
\hline
\end{tabular}

The overall average score for the gymnasts' emotional distress during the basic training period was 23.5, which corresponds to a low level of distress according to the Cognitrom reference data. 
Descriptive statistics for the overall score of emotional distress calculated for the precompetitive training period are shown in Table 3.

Table 3. Descriptive statistics for the overall score of emotional distress - Precompetitive training period

\begin{tabular}{lc}
\hline Overall score of emotional distress - Precompetitive training period \\
\hline Mean & 37.7 \\
Standard Error & 3.04795 \\
Median & 39 \\
Mode & 32 \\
Standard & \\
Deviation & 9.638465 \\
Sample Variance & 92.9 \\
Kurtosis & 0.736234 \\
Skewness & 0.20471 \\
Range & 35 \\
Minimum & 21 \\
Maximum & 56 \\
Sum & 377 \\
Count & 10 \\
\hline
\end{tabular}

The overall average score for the gymnasts' emotional distress during the precompetitive training period was 37.7, which also corresponds to a low level of distress according to the Cognitrom reference data. However, the tTest applied to the data has confirmed that there is a significant statistical difference $(\mathrm{p}<.05)$ between the two assessments (Table 4).

Table 4. t-Test: Paired Two Sample for Means - Basic and precompetitive periods

\begin{tabular}{lcc}
\hline & Variable 1 & Variable 2 \\
\hline Mean & 23.5 & 37.7 \\
Variance & 70.05556 & 92.9 \\
Observations & 10 & 10 \\
Pearson Correlation & 0.375314 & \\
Hypothesised Mean Difference & 0 & \\
Df & 9 & \\
$\mathrm{t}$ Stat & -4.4375 & \\
$\mathrm{P}(\mathrm{T}<=\mathrm{t})$ one-tail & 0.000815 & \\
$\mathrm{t}$ Critical one-tail & 1.833113 & \\
$\mathrm{P}(\mathrm{T}<=\mathrm{t})$ two-tail & 0.001629 & \\
$\mathrm{t}$ Critical two-tail & 2.262157 & \\
\hline
\end{tabular}

Additionally, we analysed the main sources of stress as perceived by the gymnasts in relation to their centralised training (Figure 1). We noticed that there were certain stressful aspects with multiple iterations in their responses: fear of technical errors, teammates' errors, school pressure and coach criticism, which slightly diminished from the initial to the final assessment. Monotony of the programme, fatigue and long training sessions were perceived more intensely in the precompetitive training period. 
International Proceedings of Human Motricity/ ICPESK 2019

Supplementary Issue of Discobolul - Physical Education, Sport and Kinetotherapy Journal, 2019

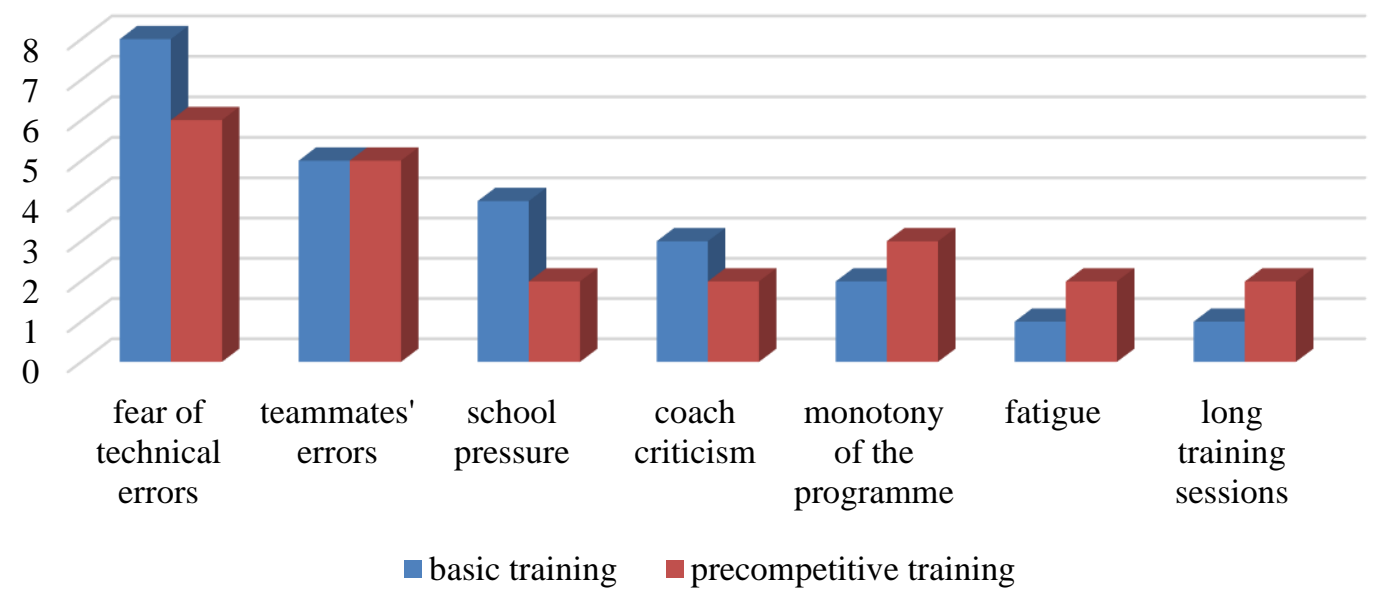

Figure 1. Main sources of stress as perceived by the gymnasts in relation to their training

We also analysed the main sources of stress as perceived by the gymnasts in relation to their participation in official competitions (Figure 2). In this regard, the gymnasts admitted that the main sources of stress, which actually diminished between the two assessments, were fear of technical errors and lack of group cohesion. Perceptions related to teammates' errors, insufficient accommodation, strong emotions and food deprivation were more intense prior to the European Championships.

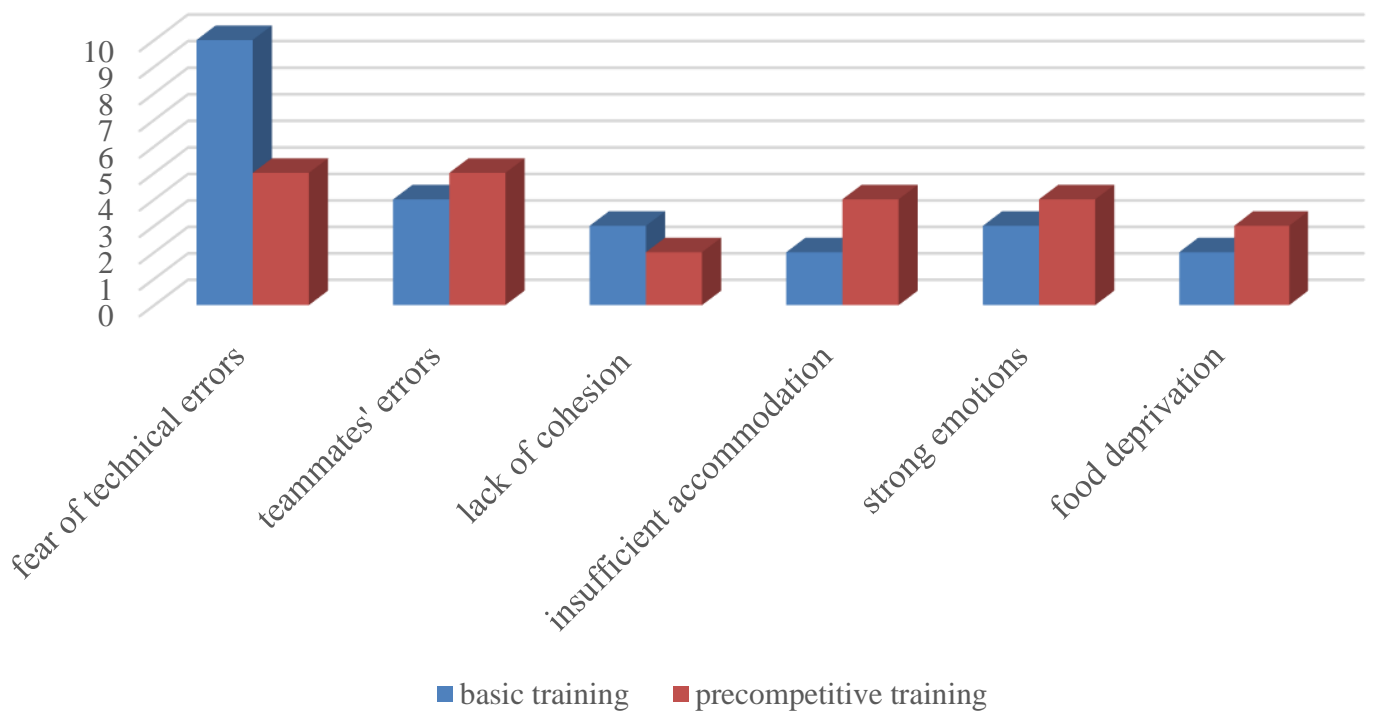

Figure 2. Main sources of stress as perceived by the gymnasts in relation to the competition

When asked to report a typical situation perceived as stressful for them, as members of the National Rhythmic Gymnastics Group, they made the following evocative statements: "Before the competition, I felt stressed because I wanted a routine without errors, and this made me feel increasingly tensed"; "During the evening, I wanted to think about what went wrong in the training, but at the same time I had to do homework for the next day"; "At the beginning of the preparation stage, I felt stressed and upset because I felt inferior to my teammates".

\section{Discussion}

Surprisingly, we have noticed that the level of emotional distress for the target group ranges between very low (in the basic training period) and low (in the precompetitive training period), which, according to the reference test battery, has no potential harmful effects on the gymnasts. We might have expected higher values of emotional 
distress, given the complex requirements of their training process: centralised national preparation, novelty of the training means (specific for the group event), large training loads, and, most of all, short training period before the main competitions. However, the data revealed some emotional fluctuations between tests, with a tendency towards increased distress, which was statistically proven. We might assume that the gymnasts were not fully connected to the competitive stress, being able to manage the sources of stress. This could be explained by their young age and lack of experience in the proper awareness of the pressure specific to major competitions.

The data collected from the group of gymnasts emphasised certain differences in their way of perceiving the sources of stress in training versus competition. In addition, the analysis of these aspects demonstrates that the gymnasts are just at a starting point in building psychological toughness specific to group event and accurate awareness of how they should cope with major competitions. Similar studies (Duda \& Gano-Overway, 1996) have emphasised several sources of stress identified by the gymnasts, covering the following areas: performance of skills (38\%), fear of evaluation (25.7\%), aspects of competition (14\%), making errors (4.1\%), expectations from self and others (4.1\%), fear of injury (2.9\%), time pressure (3.5\%) and environmental conditions (1.8\%).

\section{Conclusion}

Numerous theoretical models are inspirational for specialists working in the field of sports science, in their attempt to describe and account for stress and anxiety in competitive sports. Rhythmic gymnastics has been a source of data for recent research focused on the analysis of performance-related competitive state anxiety, precompetitive anxiety and their effect on performance, or how to cope with emotions in both training and competitions.

Our study is meant to support the initiative of the Romanian Olympic Committee to create from scratch a junior training centre for rhythmic gymnastics group event.

Even if our research has not emphasised high levels of emotional distress, some emotional fluctuations between assessments were revealed as the main competitions approached. In the absence of proper stress management, this might lead to fragile emotional behaviour reflected in poor results in competitions.

This complex sport, which is also stressful especially for young and inexperienced athletes, requires psychological counselling and training to be provided not only by the coach, but also by professionals who have a broad view of stress in gymnastics.

Further research is certainly needed on different variables influencing stress level and coping mechanisms. Correlating the gymnasts' personality traits with their emotional distress might bring interesting data for understanding the performers' psychological echo and the effectiveness of their performance in competition.

\section{References}

Anshel, M. H. (2001). Qualitative validation of a model for coping with acute stress in sports. Journal of Sport Behavior, 24(3), 223-246. Retrieved from https://www.cabdirect.org/cabdirect/abstract/20013116719

Bobo-Arce, M., \& Méndez-Rial, B. (2013). Determinants of competitive performance in rhythmic gymnastics: A review. Journal of Human Sport \& Exercise, 8(3), 711-727. doi: 10.4100/jhse.2013.8.Proc3.18

Cohn, P. (2018). Why fear of failure leads to tentative play. Retrieved from https://www.peaksports.com/sportspsychology-blog/why-fear-of-failure-leads-to-tentative-play/

Cognitrom Assessment System (CAS++ v.2). (2012). Retrieved from http://www.cognitrom.ro/produs/evaluarepsihologica/

Dantzer, R. (2007). Stres. In R. Doron \& F. Parot (Dir.), Dicţionar de psihologie [Dictionary of psychology]. Bucureşti: Humanitas.

Daroglou, G. (2011). Coping skills and self-efficacy as predictors of gymnastic performance. The Sport Journal, 14(1). Retrieved from https://thesportjournal.org/article/coping-skills-and-self-efficacy-as-predictors-ofgymnastic-performance/

Duda, J. L., \& Gano-Overway, L. (1996). Anxiety in elite young gymnastics: Part II. Sources of stress. Retrieved from https://www.researchgate.net/publication/229109252_Anxiety_in_Elite_Young_Gymnasts_Part_II__Sources_of_Stress

Fan, L., Cao, C., \& Tang, H. (2004). Influence of anxiety state on the performance stability of top-level rhythmic gymnasts. In V. Klisouras (Ed.), Athens 2004: Pre-Olympic Congress. Thessaloniki, Greece: Aristotle University of Thessaloniki, Department of Physical Education \& Sport Science. Retrieved from 
https://cev.org.br/biblioteca/influence-of-anxiety-state-on-the-performance-stability-of-top-level-rhythmicgymnasts

Fletcher, D., \& Fletcher, J. (2005). A meta-model of stress, emotions and performance: Conceptual foundations, theoretical framework, and research directions. Journal of Sports Sciences, 23, 157-158. doi: $10.1080 / 02640410512331334413$

Gibson, A. (1998). Mental toughness. New York: Vantage Press.

Hahn, E. (1987). In E. Beyer (Ed.), Dictionary of sports science. Schorndorf: Karl Hofmann Verlag.

Jemni, M., Sands, W., Salmela, J., Holvoet, P., \& Gateva, M. (2011). The science of gymnastics. London and New York: Routledge, Taylor \& Francis Group.

Jones, G., Hanton, S., \& Connaughton, D. (2002). What is this thing called mental toughness? An investigation of elite sport performers. Journal of Applied Sport Psychology, 14(3), 205-218. https://doi.org/10.1080/10413200290103509

Loehr, J. E. (1995). The new toughness training for sports. New York: Plume.

Martens, R., Vealey, R. S., \& Burton, D. (1990). Competitive anxiety in sport. Champaign, IL.: Human Kinetics.

Pehlivan, C., Nalçakan, C. G., \& Ergan, S. A. (2018). Elite athletes' characteristics in esthetic sports related to body composition, physiology, bone mineral density and nutrition. International Journal of Sports Exercise \& Training Sciences, 4(1), 6-18. https://doi.org/10.18826/useeabd.339738

Tsopani, D., Dallas, G., \& Skordilis, E. K. (2011). Competitive state anxiety and performance in young female rhythmic gymnasts. Perceptual and Motor Skills, 112(2), 549-560. https://doi.org/10.2466/05.09.20.PMS.112.2.549-560

Yeh, L. (2016). The effect of stress coping techniques in sports (CMC Senior Theses: Paper 1240). Retrieved from http://scholarship.claremont.edu/cmc_theses/1240 